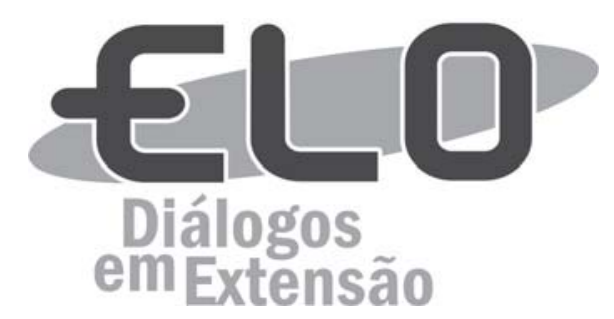

\title{
Os professores e as cidades (in)visiveis: conhecimentos gerados num processo de produção audiovisual coletiva
}

\author{
Giuliana Franco Leal ${ }^{1}$ e Rafael Nogueira Costa ${ }^{2}$
}

\begin{abstract}
Resumo: Esse artigo aborda analiticamente resultados de um projeto de extensão universitária de formação continuada de professores da educação básica da rede municipal. As oficinas de formação continuada realizadas durante o projeto tiveram por finalidade discutir os aspectos visíveis e invisiveis da cidade Macaé (RJ) e culminaram na produção colaborativa de um documentário sobre o tema "Macaé invisível", realizado nesse mesmo local. Exploramos, portanto, neste texto, as visões dessa cidade expressas pelos professores e suas relações com o processo educativo. Este trabalho de extensão possibilitou perceber a forte sensibilização dos professores com as populações e com os trabalhos invisibilizados - incluindo seus estudantes o próprio trabalho docente.
\end{abstract}

Palavras-chave: Educação. Invisibilidade social. Questões urbanas. Produção audiovisual.

Área Temática: Educação.

\section{Teachers and the invisibles cities: knowledge generated in collective process of audiovisual production}

\begin{abstract}
We analyze the results of a university extension project of continuing education of basic education teachers. Focused on teachers of the municipal network, the workshop discussed the visible and invisible aspects of the city and culminated in the collaborative production of a documentary on the theme "Invisible Macaé", on the same place. So we explore, in this text, the visions of this city expressed by teachers and their relationships with the educational process. This extension project allowed teachers to reflect collectively about invisible populations and invisible jobs - including their students and their own teaching work.
\end{abstract}

Keywords: Education. Social invisibility. Urban issues. Audiovisual production.

\section{Los docentes y las ciudades invisibles: conocimiento generado en el proceso colectivo de producción audiovisual}

Resumen: Este artículo aborda analíticamente resultados de un proyecto de extensión universitaria de formación continuada de profesores de educación básica. El curso tuvo como objetivo discutir los aspectos visibles e invisibles de la ciudad donde ocurrió la producción colaborativa de un documental sobre el tema "Macaé Invisible", realizado em ese mismo lugar. Por conseguiente, exploramos, en este texto, las visiones de la ciudad expresadas por los profesores y sus relaciones con el proceso educativo. Este proyecto de extensión permitió a los profesores reflexionar colectivamente sobre las poblaciones y trabajos invisibilizados - incluyendo a sus alumnos y el propio trabajo docente.

Palabras clave: Educación. Invisibilidad social. Cuestiones urbanas. Producción audiovisual.

\footnotetext{
${ }^{1}$ Cientista social, Doutora em Sociologia pela Unicamp e Professora da Universidade Federal do Rio de Janeiro com atuação no Núcleo em Ecologia e Desenvolvimento Socioambiental de Macaé (NUPEM), no Campus Macaé e no Programa de Pós-Graduação em Ciências Ambientais e Conservação (PPGCiAC/UFRJ). E-mail: giulianafrancoleal@yahoo.com.br

${ }^{2}$ Biólogo, Doutor em Ciências Ambientais pela UERJ e Professor da Universidade Federal do Rio de Janeiro com atuação no Núcleo em Ecologia e Desenvolvimento Socioambiental de Macaé (NUPEM) e no Programa de Pós-Graduação em Ciências Ambientais e Conservação (PPGCiAC/UFRJ). E-mail: rafaelnogueiracosta@gmail.com.
} 


\section{Os professores e as cidades (in)visíveis: conhecimentos gerados num processo de produção audiovisual coletiva}

Você já passou por mim

E nem olhou pra mim

Você já passou por mim

E nem olhou pra mim

Acha que eu não chamo atenção

Engana o seu coração

Acha que eu não chamo atenção

Ninguém viu, ninguém viu, ninguém acha você

Invisível, invisível, ninguém acha você

Há maneiras de ver, maneira de ser

Maneira de crer, maneira de ver

Cara-metade, cara-metade, quero te ver na cidade.

Baiana System

Invisível

(Russo Passapusso, Roberto Barreto, SekoBass, Filipe Cartaxo)

\section{Introdução: olhares e educação}

Muitas pessoas, objetos e eventos estão diante de nossos olhos, diariamente, mas nem tudo é realmente visto. Pessoas passam despercebidas, processos permanecem invisíveis, objetos são ignorados. A visibilidade é construída socialmente. A invisibilidade, também. Tornar visível algo ou alguém é um processo de mudança, direção e treino do olhar. A educação - despertando, dirigindo e sensibilizando olhares - é certamente um dos instrumentos de visibilização de pessoas, objetos e processos.

Professores lidam diretamente com a educação dos olhares de seus alunos. A profundidade de campo, o ajuste do foco e a proximidade com os objetos são expressões utilizadas pelos amantes da fotografia e do cinema. Entretanto, o uso desas expressões no campo educacional é capaz de estimular reflexões interessantes. Trazer essas questões à reflexão pode compor a criação de mais instrumentos educativos por parte dos educadores. É sobre uma experiência de discussão e evidenciação dos processos de invisibilização/visibilização que trata esse artigo.

Discutimos aqui uma experiência de extensão universitária que reuniu professores e estudantes da Universidade Federal do Rio de Janeiro (UFRJ) - Campus Macaé, além de professores da Universidade do Estado do Rio de Janeiro (UERJ) e da Universidade Federal do Estado do Rio de Janeiro (UNIRIO) e professores da educação básica do município de Macaé (RJ) numa oficina de formação continuada, com o intuito de produzir um filme documentário colaborativo com o tema "Macaé invisível".

O diálogo e a colaboração entre atores situados em diferentes instituições é o eixo central dessa experiência e vai ao encontro do propósito da educação superior conforme aponta o artigo 43 da Lei de Diretrizes e Bases da Educação (LDB), ao destacar a promoção da "extensão, aberta à participação da população, visando à difusão das conquistas e benefícios resultantes da criação cultural e da pesquisa científica e tecnológica geradas na instituição" (BRASIL, 1996). As atividades de extensão nas universidades brasileiras possibilitam uma apropriação por uma parte maior da sociedade dos espaços de produção de conhecimento científico. É como se fossem criados caminhos distintos para entrada nas universidades. Dessa forma, a UFRJ assume o compromisso de regularizar nos currículos das 
graduações a inserção de dez por cento da carga horária para atividades de extensão, que serão executadas de maneiras diversas:

As atividades de Extensão Universitária compreendidas como um processo interdisciplinar educativo, cultural, científico e político que promove a interação transformadora entre universidade e outros setores da sociedade serão executadas sob a forma de Programas, Projetos, Cursos, Eventos e Disciplinas (Art. 2, Resolução CEG $\mathrm{n}^{\mathrm{o}} 02 / 2013$ - UFRJ).

Nesse caminho, além da riqueza dessa experiência para a formação contínua dos professores envolvidos (tanto da Universidade como das escolas, além dos professores em formação e dos alunos de uma licenciatura), temos também a oportunidade de, a partir dessa experiência, discutir uma questão importante para pensar o ensino e a pesquisa: a relação entre professores e a cidade onde trabalham e como isso se relaciona com os processos educativos dos quais participam.

\section{Objetivos}

Temos como objetivo nesse texto responder a seguinte questão: o que os diálogos, o processo de produção coletiva e os registros audiovisuais gerados pelos professores a partir dessa experiência formativa expressam sobre sua visão da cidade onde trabalham - em especial, sobre o que é visível e invisível na mesma? A partir daí, podemos levantar algumas ideias sobre como o processo de visibilização do que consideram invisível na cidade pode se refletir no processo educativo.

\section{Metodologia}

Os autores deste artigo foram professores responsáveis pela elaboração e execução do curso, idealizado pelo segundo autor ${ }^{3}$. É a partir desse lugar - participantes e observadores do processo que fazemos a descrição, análise e reflexões abaixo apresentadas. Usamos como material de análise os áudios dos encontros, os questionários respondidos pelos cursistas e o material filmado pelos mesmos. O uso de todo esse material foi autorizado pelos seus autores por meio de um termo de consentimento livre e esclarecido. Parte da metodologia adotada no encontro é fruto de um acúmulo de pesquisas e atividades formativas, que articulam a relação entre educação ambiental e cinema, desenvolvidas pelo Coletivo de Pesquisa em Cinema Ambiental (CUCA/UFRJ). Ao longo dos últimos anos foram produzidos diversos encontros em Unidades de Conservação, escolas, universidades e museus (FUENTES, COSTA e RUTA, 2016; COSTA e BRANQUINHO, 2016; COSTA, BRANQUINHO e SÁNCHES, 2018).

$\mathrm{Na}$ análise dos dados, foram usadas técnicas de categorização temática da análise de conteúdo (Bardin, 2009): em função de nossos objetivos, foi definido um tema central para a criação das categorias (a saber: quem são os invisíveis da cidade?) e em seguida, a partir da leitura repetida do material (parte dele produzido originalmente na forma escrita e parte dele gravado e transcrito), respostas à questão-tema com semelhanças semânticas foram agrupadas e sintetizadas em categorias que pudessem agrupar consistentemente o conjunto das noções de "invisíveis" apresentadas. Em um segundo momento, as menções aos conteúdos das categorias foram contabilizados e interpretados em conexão com os temas que apareceram com maior frequência nas falas e produções audiovisuais dos sujeitos participantes da pesquisa.

\section{Desenvolvimento}

O projeto de extensão “Cinema e Educação Ambiental: A produção coletiva do filme 'Macaé invisível'" foi criado a partir de uma demanda da Secretaria Municipal de Educação, de cursos formativos para professores. A procura pelo curso - que ocorreu na forma de oficina - foi significativa, quando comparada a outros cursos oferecidos na mesma oportunidade. Participaram do projeto 26 professores de diferentes disciplinas da educação básica (Artes, História, Geografia, Ciências,

${ }^{3}$ Esta proposta faz parte de uma etapa do percurso de pesquisa da tese de doutorado defendida na Universidade do Estado do Rio de Janeiro (UERJ), que traz reflexões sobre os encontros entre educação ambiental e cinema em diferentes contextos (COSTA, 2016). 
Matemática, Educação Física, Língua Portuguesa e Inglês), além de três alunos do Curso de Licenciatura em Ciências Biológicas da UFRJ Macaé, sendo uma bolsista do projeto. Dois professores da UFRJ Macaé e um professor da UNIRIO coordenaram a oficina. O propósito do encontro era discutir a rede de invisibilidade e visibilidade do município de Macaé, bem como expressá-la de forma audiovisual. Ao longo do curso, produziu-se, de forma coletiva e colaborativa, um experimento audiovisual sobre o tema.

Como principais referências teóricas, tivemos a perspectiva de Bruno Latour (2009), com ênfase aos conceitos de plasma e de coletivos, a abordagem de Richard Sennet (2014) sobre a passividade dos corpos nas cidades e a elaboração de Braga (2004) da noção de invisibilidade social, compreendida como o desaparecimento intersubjetivo de uma pessoa no meio de outras. Metodologicamente, os encontros assumiram o formato de oficinas pautadas pela perspectiva dialógica de Paulo Freire (1996). Questionamentos a partir de situações cotidianas e a busca de respostas construídas por meio da troca de saberes foram a base da construção coletiva de um filme que expressasse as visões dos participantes das oficinas sobre os temas propostos. Os professores responsáveis por ministrar as atividades atuaram como provocadores e facilitadores.

Houve cinco encontros, um por semana, sempre nas tardes de terça-feira, entre setembro e outubro de 2015. No primeiro dia, foi realizada uma rodada de apresentações de cada participante (dando como informações o nome, disciplina lecionada, escolas onde atua, razões da escolha do curso e expectativas); apresentação da proposta pelos facilitadores da oficina; um processo de obtenção do consentimento livre e esclarecido para que usássemos dados obtidos na oficina para pesquisa e publicação, culminando com a assinatura de um termo de consentimento; uma rodada de discussão sobre o que cada um considera visível e invisível na cidade de Macaé; preenchimento de respostas individuais a um questionário com quatro questões, a saber: "1. Se você pudesse definir a cidade de Macaé, como você definiria?; O que vocês entendem como problemas socioambientais na cidade de Macaé?; 3. Quem/o que são os invisíveis na cidade?; 4. Quem/o que são os mais visíveis?".

No segundo encontro, vários materiais audiovisuais e textos foram trazidos e apresentados pelos facilitadores da oficina com o objetivo de suscitar ideias e discussões sobre o tema da invisibilidade nas cidades. Inicialmente, lemos e discutimos uma crônica de Eliane Brum (2015) sobre segregação. Demos ênfase à invisibilidade das pessoas segregadas pela população das classes mais altas. Na sequência, a leitura de dois contos do livro Cidades Invisíveis de Italo Calvino (1990) levaram a discussões voltadas para a memória sobre a cidade e os símbolos nela contidos. Depois, foi apresentado o livro Paris invisível, de Bruno Latour (2009), discutindo-se a apreensão das cidades pelo olhar de um antropólogo e uma fotógrafa. Por fim, assistiu-se aos primeiros minutos do filme de Woody Allen, Meia Noite em Paris, focando-se na edição das imagens como forma de passar determinada imagem sobre a cidade e velar outras informações. A sessão foi fechada ao assistirmos um vídeo institucional sobre Macaé, feito pela prefeitura e apresentado originalmente na Feira Brasil Offshore 2015, um evento de grande porte ligado à economia do petróleo e com ampla participação do governo local, e discutimos criticamente as mensagens passadas pelo mesmo.

O terceiro encontro foi dedicado a assistir e discutir o filme Mundo Invisível ${ }^{4}$, também houve uma aula com uma estagiária do projeto sobre a edição de filmes e, por fim, deu-se uma breve exposição pelos participantes de ideias sobre os registros audiovisuais que seriam feitos. Entre esse encontro e o seguinte, os registros foram efetuados com os instrumentos que cada um tivesse disponíveis - telefones celulares, gravadores ou qualquer outro equipamento que permitisse gravar imagem e/ou áudio. $\mathrm{Na}$ sessão seguinte, todos assistiram as produções de cada um. Debateram-se, então, possíveis eixos condutores para agregar todas as contribuições com sentido e coerência. Uma das estagiárias foi responsável pela edição do material, sob a supervisão do coordenador do curso. Foi agregada a contribuição de um membro externo especialmente convidado para fazer a trilha sonora do documentário. $\mathrm{O}$ filme ${ }^{5}$ foi apresentado no encontro seguinte, seguido por uma rodada de opiniões sobre o produto final e avaliações sobre a experiência de participar dessa construção.

\footnotetext{
${ }^{4}$ Esta proposta faz parte de uma etapa do percurso de pesquisa da tese de doutorado defendida na Universidade do Estado do Rio de Janeiro (UERJ), que traz reflexões sobre os encontros entre educação ambiental e cinema em diferentes contextos (COSTA, 2016).

${ }^{5} \mathrm{O}$ material audiovisual está disponível nos seguintes endereços eletrônicos: www.cuca.bio.br e https://www.macae.ufrj.br/nupem/
} 


\section{Resultados e discussão}

\subsection{A cidade e os professores}

No seu passado recente, Macaé cresceu, economicamente e em população, em função da instalação da Petrobras e das empresas que a seguiram. Com uma história rica e recheada de complexidade, como a presença de índios, construção de igrejas pelos jesuítas, presença de porto para escoamento de produção de açúcar da região norte do Estado, instalação de ferrovias, plantio de café, entre outros, o território foi se transformando desde os séculos anteriores. Entretanto, dos ciclos econômicos, sem dúvidas, o ciclo do petróleo foi aquele que mais deixou marcas pela sua presença. Construção de portos, terminais de recebimento de gás, gasodutos, modificações ambientais, ocupações em áreas impróprias, são sinais da presença da atividade petrolífera em Macaé.

Em 1970, quatro anos antes da instalação da Petrobras, o município contava com 47.221 habitantes. Em 40 anos, teve um aumento de 551,9\% no número de habitantes (Terra e Ressiguier, 2010), chegando a mais de 224 mil habitantes, segundo o último censo demográfico, realizado em 2010. Segundo Paganoto (2008), o crescimento populacional foi rápido e se deu em função da significativa taxa de imigração de trabalhadores que procuraram e eventualmente ocuparam postos de trabalho gerados pela indústria do petróleo. Macaé constitui-se como uma cidade cuja economia e as atividades laborais de grande parte de sua população baseiam-se na economia do petróleo. O crescimento da cidade, contudo, foi marcado por acentuada desigualdade e indicadores sociais de precariedade (Pizzol, 2008). Expandiram-se favelas e ocupações ilegais de terrenos e os serviços urbanos têm sido insuficientes (Silva Neto, 2007). Além disso, o crescimento econômico de Macaé fez-se acompanhar de degradação ambiental (Silva Neto, 2007).

Além dos trabalhadores que migram para a cidade, há muitos que residem em outras cidades e se deslocam a ela para trabalhar. Paganoto (2008) identificou deslocamentos de longa distância para trabalho ou estudo de outras cidades para Macaé por pessoas residentes em 207 diferentes municípios. Isso acontece em grande parte por causa dos postos de trabalho off shore, em que os trabalhadores permanecem vários dias embarcados, folgando vários dias na sequência. Mas a migração de trabalhadores para a cidade também tem sido alta na área da educação. Souza (2017) mostra que 43,66\% dos professores que trabalhavam em Macaé no ano 2013 não residem na cidade. Ela interpreta como possíveis causas o fato da rede municipal oferecer um salário mais elevado do que a média, além da baixa oferta de cursos de formação de professores na cidade.

Esse "afastamento" dos professores em relação ao cotidiano da cidade, simbolizada pela moradia em outros municípios, dificulta a percepção dos problemas e potencialidades nos quais os seus alunos estão íntimos/imersos/radicados. Dessa forma, o ensino tende a ser descontextualizado, com pouca reflexão local e, planejado com base em vivências que não correspondem aos processos locais. Pensando nisso, acreditamos que o uso do cinema como mediação e reflexão possa contribuir para a formação docente, no caminho para ampliar a percepção sobre as diferentes dimensões da cidade.

\section{2. "Macaé invisível" pelos olhares dos professores}

Dados os objetivos desse texto, apresentados na introdução, as análises e reflexões concentram-se sobre o que foi dito, feito e apresentado pelos professores da educação básica participantes até o quarto encontro. Não nos interessa, nesse momento, o produto final, já que ele incorpora uma edição feita pelos organizadores da oficina sem a participação efetiva da coletividade.

A partir dos relatos dos participantes desse encontro, três ideias se destacaram para a escolha desse curso: o interesse pelos temas ambientais, a motivação de produzirem algo e o interesse por se apropriarem dos instrumentos audiovisuais como mais uma ferramenta didática. Alguns professores comentaram a defasagem dos métodos de aula usados em relação aos conhecimentos dos alunos quanto às tecnologias de produção de vídeos:

“Eu estou muito defasada, não consigo acompanhar, fazer com que eles [os estudantes] fiquem interessados. Quando eu vi o tema do cinema, eu fiquei bem interessada para fazer algo com os nossos alunos, eles têm facilidade com os aparelhos. Eu não estou conseguindo reter os aparelhos, eles querem continuar. Então eu tenho que fazer algo para que eles possam de alguma forma fazer com que eles estudem mais e fiquem mais atentos". 
“ A gente propõe o trabalho, mas eles sabem mais que a gente."

"Eu trabalho de quinta a oitava [séries] e a gente vê que se hoje você não estiver acompanhando a tecnologia, eles te dão um banho mesmo."

Trata-se de professores que atuam dentro de um contexto global de avanço tecnológico, com o qual a escola, com seus métodos antigos de aulas (muito semelhantes às práticas disciplinares do século XIX), mantém uma distância, que afasta dela os estudantes. Demo (2011) comenta a necessidade dos professores serem protagonistas na criação de conhecimentos, caso queriam ser mediadores para que os estudantes aprendam a aprender - o que é uma necessidade patente em um mundo em constante transformação (BAUMAN, 2009).

As reflexões dos professores caminham na mesma direção da Lei de Diretrizes e Bases da Educação (BRASIL, 1996), que teve seu texto alterado com a inserção do artigo 26, obrigando a exibição de filmes de produção nacional nas escolas de educação básica (BRASIL, 2014). Mais do que exibir filmes nacionais, trata-se de refletir sobre a construção, trazendo para o debate a manipulação da imagem e as distintas maneiras de se posicionar subjetivamente; faz parte dessa proposta, produzir conjuntamente, no lugar de exibir o ponto de vista do outro.

Ao longo das oficinas, aquilo que é invisível na cidade foi apreendido de várias maneiras: por um formulário de perguntas que os professores responderam após o primeiro encontro, em que uma das questões era: "Quem/o quê são os invisíveis na cidade?"; pelas conversas ao longo do projeto; pelas produções audiovisuais geradas.

Nas respostas aos questionários ${ }^{6}$, sobre quem são os invisíveis da cidade, aparecem mais recorrentemente os pobres e moradores de periferias (8 menções). Além disso, três pessoas generalizam "a população" como sendo marginalizada; houve três menções à "natureza" ou "patrimônio natural; alguns se referem a outras parcelas específicas da população: migrantes, "pessoas locais", idosos, jovens, agricultores, pescadores, "não inseridos no setor petroleiro".

A ideia de uma cidade desigual emergiu algumas vezes nas rodas de conversas, sendo a desigualdade uma situação invisibilizadora. Pobres e moradores da periferia são equivalentes nessa visão. Muito se comentou sobre uma peculiaridade da cidade: a ponte. Trata-se de uma via de passagem que divide a cidade em duas: de um lado, o centro da cidade, com boa parte do comércio, das agências bancárias, dos restaurantes, shopping centers, muitos escritórios das empresas e bairros prioritariamente de classe média, com melhor infraestrutura e transporte; de outro lado, os bairros com menos infraestrutura e população mais pobre, onde se encontra a maior parte das favelas. Um dos professores comenta que existe mesmo uma diferença entre as escolas "para cá e para lá da ponte": há menos investimento naquelas do "lado pobre", pois são mesmo menos visíveis como plataforma eleitoral.

É ponto de acordo geral que a dinâmica da cidade se estabelece em função da economia do petróleo, turvando o resto. Nas rodas de conversa realizadas na oficina, um dos professores conta o processo de escolha do slogan "capital do petróleo" como uma estratégia política de valorização de um setor da economia, orquestrada pelos que tirariam vantagens daí. Outro professor comenta que "chamar essa cidade de capital do petróleo parece uma neblina que não deixa enxergar o resto".

Nos questionários, são citados como invisíveis a "atuação do governo nas áreas não petroleiras" e outros serviços públicos (três vezes mencionados), em especial as escolas municipais, mencionadas por um dos professores. A invisibilização de toda aquela população mencionada anteriormente (que é no caso uma ignorância proposital de sua existência, necessidades e direitos) é a outra face da invisibilidade dos serviços públicos.

As considerações dos professores expostas acima, seja as obtidas por meio dos questionários ou as que emergiram na discussão livre, são as mais espontâneas, pois ocorreram antes dos direcionamentos de leituras e discussões feitos pelos facilitadores da oficina. Portanto, estão mais próximas das ideias que os participantes já traziam a respeito do que é visível ou invisível na cidade. Os condicionantes existentes até aqui se referiam basicamente ao tema da oficina, classificado dentro da categoria "educação ambiental", e aos objetivos apresentados inicialmente, de fazer uma produção coletiva sobre a cidade a partir dos que os participantes da oficina considerassem invisível na cidade. Mesmo assim, questões propriamente ambientais (que estariam mais passíveis de terem sido induzidas) foram menos presentes do que aquelas relativas às desigualdades sociais.

${ }^{6}$ Foram respondidos 19 questionários e aqui estão contabilizadas todas as respostas, podendo haver várias menções diferentes feitas por pessoa. 
Contudo, após as leituras e discussões, que muitas vezes se centraram nas questões das desigualdades sociais, não foi este o tema mais recorrente dos registros feitos pelos professores individualmente. Esse fato levanta a hipótese de que o tema mais produzido foi algo que de fato preocupa os professores em seu dia a dia. Nas produções audiovisuais individuais, a educação é o tema principal das situações de invisibilidade. Metade dos participantes que contribuíram com registros audiovisuais falam sobre professores, estudantes e suas relações, principalmente em escolas, mas também - em um caso - em um projeto de educação informal pelo esporte. São as escolas públicas que aparecem nos vídeos. Invisível é o trabalho do professor, que em um dos vídeos aparece acordando de madrugada e demorando três horas para chegar ao trabalho pelo transporte público, mas, como diz o narrador, "isso ninguém vê". Invisível é o esforço de uma professora para incluir alunos com deficiência, sem nenhum tipo de suporte pedagógico vindo da escola. Invisíveis são os próprios estudantes, especialmente os que apresentam deficiências e os mais velhos, trabalhadores, migrantes, alunos da Educação de Jovens e Adultos (EJA).

Outro tema que aparece em metade das produções audiovisuais dos participantes das oficinas é a economia do petróleo - central na dinâmica da cidade filmada. Ela se mostra pelo símbolo das embarcações petroleiras, pelos postos de gasolina, pelas empresas do ramo, pela placa de "bem-vindo à capital do petróleo". Mas, assim como o processo de urbanização - registrado pela concentração de moradias, prédios, comércios e empresas em geral, estradas e ruas (bem ou mal) asfaltadas -, a economia do petróleo é mostrada como algo bem visível e quase sempre, para acentuar seu contraste, aspectos da vida urbana que se tentam invisibilizar: a degradação ambiental, a pobreza urbana ou mesmo a beleza de paisagens.

A degradação ambiental aparece em cinco dos 18 registros audiovisuais realizados pelos professores da educação básica: são imagens de lixo na beira da praia ou do rio, desmatamento da restinga, valão com água podre. Essa poluição urbana está, na maioria das vezes, associada à pobreza, cinco vezes registrada nos vídeos, especialmente por imagens de moradias precárias e bairros periféricos sujos e mal equipados.

A degradação ambiental citada pelos professores e capturada pelas suas lentes, também é registrada em artigos científicos produzidos por diferentes pesquisadores. Por exemplo, em estudos sobre alterações ambientais no estuário do rio Macaé, com modificações em níveis celulares dos peixes (BEREGER et al., 2018; CONCEIÇÃO et al., 2017; SANTIAGO et al., 2016). Diminuição da quantidade e qualidade da água frente as demandas presentes e futuras deste recurso devido ao uso inadequado do solo (ESTEVES et al., 2015).

Quatro registros audiovisuais que se referem às belezas naturais da cidade, mostrando-as restritas aos bairros de classe média ou alta - como no vídeo em que a paisagem à beira do rio vai se degradando quando passa de um condomínio de alto padrão para uma favela à beira do mangue - ou revelam-nas escondidas ou eliminadas como consequência do primeiro plano dado à economia petroleira e do processo desordenado de urbanização. Um dos vídeos, por exemplo, mostra uma vista pequena do mar atrás de várias construções, a partir da janela da casa da professora, que explicou na oficina que há alguns anos, conseguia ter uma bela vista do mar a partir da sua varanda, o que ela chamou de "pedacinho do mar". Em outro registro, conteiners cobrem parte da serra.

A nostalgia de uma cidade cuja calma e beleza se perderam com o acelerado processo de crescimento das últimas quatro décadas é um traço que já havia aparecido nas rodas de conversa, por parte daqueles professores que cresceram na cidade ou que nela passavam suas férias de infância, e o tema volta a se repetir nos vídeos no contraste entre fotos de uma bucólica "Macaé de antigamente" e da agitada e degradada "Macaé de hoje" e em narrativas que lamentam a perda da beleza e do uso de certas áreas da cidade para o lazer.

Outros temas aparecem mais isoladamente e, por isso, não serão aqui discutidos: há um registro sobre o grafite, um da área rural do município, um de cachorros abandonados e outro de pessoas com deficiência física, com dificuldades para se deslocarem nas calçadas sem nenhum tipo de acessibilidade para cadeirantes.

\section{Conclusões: (in)visibilidade e educação}

Parte da população da cidade - especialmente pobres e migrantes, entre os quais a maior parte dos estudantes das escolas públicas - é considerada invisível pelos professores que participaram do curso. Do produto gerado pelos professores, conclui-se que, em sua visão, visibilizadas devem ser as 
condições de vida dos que habitam a cidade: a infraestrutura urbana, com seus defeitos; as degradações ambientais e a desigual repartição dos recursos entre os moradores da cidade. Visibilizada deve ser toda a dinâmica da cidade que não é contemplada no direcionamento de recursos para os setores já privilegiados da economia. Os estudantes aos quais esses professores ensinam são parte dessa população invisibilizada e a precariedade das condições de trabalho desses professores reflete o descaso com políticas para o conjunto dessa população.

A invisibilização do trabalho dos professores é consequência disso e eles se levantam contra ela nesse filme. Visibilizado deve ser o olhar sobre o trabalho dos educadores: seus esforços, sua jornada de trabalho, o processo de ensino-aprendizagem e, junto com isso, seus alunos da rede pública.

O processo de problematização dos olhares se mostrou um caminho produtivo para estabelecer uma relação crítica com a cidade, que promova a reflexão sobre os pontos de vista existentes e sobre o próprio lugar de onde se olha a realidade. O olhar dos professores foi bastante crítico aos problemas socioambientais e à desigualdade social. Foi ao lado dos que sofrem esses problemas que eles se colocaram.

O interesse nessa oficina exprime o desejo desses professores de serem sujeitos e de serem produtores de sua própria visão. A cidade que os professores veem é a cidade que não os enxerga - nem a eles, como profissionais, nem ao seu trabalho, nem aos seus alunos. Tornar isso visível em um filme pode significar lançar luz sobre esse problema. O resultado revela que os professores precisam de protagonismo social para si, para seus alunos e para a educação.

Realizar essa experiência com os docentes abriu novas perspectivas e possibilidades de uso do audiovisual. Entre seus desdobramentos, está a construção de um festival de cinema buscando ampliar os olhares sobre as camadas das cidades que compõe a "Capital do Petróleo".

\section{Referências bibliográficas}

BARDIN, L. Análise de conteúdo. Lisboa: Edições, 2009.

BAUMAN, Z. Vida líquida. Rio de Janeiro: Zahar, 2009.

BRASIL. Lei número 9394, 20 de dezembro de 1996. Lei de Diretrizes e Bases da Educação Nacional. Brasilia, DF, 1996.

BRASIL. Lei $n^{0}$ 13.006, de 26 de junho de 2014. Acrescenta $\S 8^{\circ}$ ao art. 26 da Lei no 9.394, de 20 de dezembro de 1996, que estabelece as diretrizes e bases da educação nacional, para obrigar a exibição de filmes de produção nacional nas escolas de educação básica. Brasília, DF, 2014. Disponível em: <http://www.planalto.gov.br/ccivil_03/_Ato2011- 2014/2014/Lei/L13006.htm>. Acesso em 25 de setembro de 2017.

BRUM, E. “Mãe, onde dormem as pessoas marrons?”. El País, Madrid, p.7, 22 jun. 2015.

COSTA, Fernando Braga da. Homens invisíveis: relatos de uma humilhação social. São Paulo: Globo, 2004.

COSTA, R.N. O audiovisual no campo da educação ambiental: hibridismos e mediações entre naturezas e culturas. 2016. Tese (Doutorado Multidisciplinar em Meio Ambiente) - Universidade do Estado do Rio de Janeiro, Rio de Janeiro.

COSTA, R.N.; BRANQUINHO, F.T.B.; SÁNCHEZ, C. Produção audiovisual na formação de professores-pesquisadores: olhares compartilhados sobre o Parque Nacional da Restinga de Jurubatiba. Desenvolvimento e Meio Ambiente (UFPR), v. 45, p. 258-273, 2018.

FUENTES, N.M.M.; COSTA, R.N.; RUTA, C. Cinema e Educação Ambiental no Parque Nacional da Restinga de Jurubatiba: Reflexões e práticas interdisciplinares e transversais. Educação e sociedade, v. 136, p. 1-19, 2016.

COSTA, R.N.; BRANQUINHO, F.T.B. A fronteira entre a comunidade e a Unidade de Conservação mastigada pela formiga-onça. Iluminuras (Porto Alegre), v. 17, p. 527-542, 2016. 
BERENGER, J. N. ; MORAIS, J. ; OLIVEIRA, M. M. ; RAIMUNDO, J. M.; MOLISANI, M.M. Effects of diesel oil and environmental quality on the enzymatic activities of a tropical estuarine catfish and implications for contamination assesment. Ecotoxicology and Environmental Contamination, v. 13, p.1, 2018.

CALVINO, I. Cidades invisíveis. São Paulo: Companhia das Letras, 1990.

CONCEICAO, M. B.; OLIVEIRA, V.; MOLISANI, M.M.; Conceição LIW. Genotoxicity of waters from Macaé river estuary to model fish Danio rerio. Arquivos de Ciências do Mar, v. 50, p. 1, 2017.

DEMO, P. Outro professor: alunos podem aprender bem como professores que aprendem bem. Jundiaí: Paco Editorial, 2011.

FREIRE, P. Pedagogia da autonomia: saberes necessários à prática educativa. São Paulo. Paz e Terra, 1996.

LATOUR, B. Paris, Cidade Invisível: O Plasma. Ponto Urbe, 2009.

PIZZOL, R.A. Riqueza e Exclusão Social: O Paradoxo dos Royalties do Petróleo. Dissertação de Mestrado em Sistemas de Gestão, UFF. 2008.

SANTIAGO, I.; MOLISANI, M.M.; NUDI, A. H.; SCOFIELD, A. L.; WAGENER, A. L.; LIMAVERDE, A. Hydrocarbons and trace metals in mussels in the Macaé coast: Preliminary assessment for a coastal zone under influence of offshore oil field exploration in southeastern Brazil. Marine Pollution Bulletin, v. 103, p. 349-353, 2016.

SENNET, Richard. Carne e pedra: o corpo e a cidade na civilização ocidental. 3.ed. Rio de Janeiro: BestBlso, 2014.

SILVA NETO, R. et al. Desafios para o desenvolvimento sustentável no Município de Macaé-RJ. Perspectivas Online, Campos dos Goytacazes, v.1, n.3, p.60-73, 2007

SOUZA, E. Migração de Professores no Rio de Janeiro: oportunidades e desafios. In: Anais da ABEP. Disponível em: <file:///C:/Users/Usu\%C3\%A1rio/Downloads/2155-6324-1-PB\%20(2).pdf>. Acesso em: 20 de setembro de 2017.

ESTEVES, F. A.; MOLISANI, M. M.; BARROS, M. P. F.; MINCARONI, M.; GONÇALVES, P.; COSTA, R. N.; MARTINS, R. L.; PETRY, A.; DI DARIO, F. Carta das Águas de Macaé. Rio de Janeiro. Cadernos NUPEM/UFRJ, 2015.

Recebido para publicação em 25/8/2018 e aprovado em 28/9/2018. 